\title{
Computational investigation of heat transfer and pressure drop in a typical louver fin-and-tube heat exchanger for various louver angles and fin pitches
}

\author{
Abdulkerim Okbaz $^{1 *}$, Ali Bahad $r$ Olcay $^{2}$, Mehmet Salih Cellek ${ }^{1}$ and Ali Pınarbaşı ${ }^{1}$ \\ ${ }^{1}$ Yildiz Technical University, Mechanical Engineering Department, Besiktas, 34349, Istanbul, Turkey \\ ${ }^{2}$ Yeditepe University, Mechanical Engineering Department, Atasehir, 34755, Istanbul, Turkey
}

\begin{abstract}
In this study 3-D numerical simulations on heat transfer and pressure drop characteristics for a typical louver fin-and- double-row tube heat exchanger were carried out. The heat transfer improvement and the corresponding pressure drop amounts were investigated depending on louver angles, fin pitch and Reynolds number, and reported in terms of Colburn $j$-factor and Fanning friction factor $f$. The heat transfer improvement and the corresponding pressure drop amounts were investigated depending on louver angles between $20^{\circ} \leq \Theta \leq 30^{\circ}$, louver pitch of $L_{p}=3.8 \mathrm{~mm}$ and frontal velocities of $U$ between $1.22 \mathrm{~m} / \mathrm{s}-3 \mathrm{~m} / \mathrm{s}$. In addition, flow visualization of detailed flow features results, such as velocity vectors, streamlines and temperature counters have been shown to understand heat transfer enhancement mechanism. The present results indicated that louver angle and fin pitch noticeably affected the thermal and hydraulic performance of heat exchanger. It has been seen that increasing louver angle, increases thermal performance while decreasing hydraulic performance associated to pressure drop for fin pitches of $3.2 \mathrm{~mm}$ and $2.5 \mathrm{~mm}$. Fin pitch determines the flow behaviour that for fin pitch of $2 \mathrm{~mm}$, increasing louver angle decreased heat transfer and pressure drop. Velocity vectors and streamlines give considerable information about the flow whether it is duct directed or louver directed. For all conditions the flow is louver directed.
\end{abstract}

\section{Introduction}

As it well known, the air side of heat exchangers have much more thermal resistance. Decreasing attempts of air side thermal resistance play an important role to improve the performance of the heat exchangers. Louver fins provide enhanced and interrupted surfaces to increase convective heat transfer. The louvers on the surface of the fins provide restarting of boundary layer and the air flow to travel across the neighbour fins and tubes. There forms a thinner thermal boundary layer and air can flow much more distance in the heat exchanger. Thus, the thermal performance of the heat exchanger increases. On the other hand, interrupted surfaces and travelling of air in longer distance increases pressure drops. Therefore, a suitable design of louvered fins is needed to enhance thermal performance of heat exchanger without prohibitive increase in the pressure drop. Researchers and engineers attempt to design more efficient louver fin heat exchangers studying various geometrical parameters experimentally and numerically.

In their experimental study, Aoki et al. [1] concluded that heat transfer coefficients at low air velocity conditions decreased with increasing fin pitch while heat transfer coefficient reached a maximum value at angle of $28^{\circ}-30^{\circ}$. They also found that at wider angles of louvers heat transfer coefficient started to decrease.
Webb and Trauger [2] defined a flow efficiency as the ratio of actual transverse distance to ideal transverse distance. Wang et al. [3] conducted experiments using commercially available louver fin-and-tube heat exchangers. They studied heat transfer and pressure drop characteristics depending on number of tube rows, fin pitch, and tube size. Kim and Bullard [4] stated that flow depth was one of the most important parameter for pressure drop characteristics of louver fin heat exchangers in their experimental study. Dejong and Jacobi [5] found that when the flow was far from bounding walls of heat exchanger, it showed spatially periodic behaviour and high heat transfer and low pressure drop occurred. In the region close to the bounding walls, large flow separation zones occurred and heat transfer decreased about 50\%. Dong et al. [6] conducted an experimental study testing air side heat transfer and pressure drop characteristics of 20 types of multi-louvered fin and flat tube heat exchangers. Vaisi et al. [7] experimentally showed that the configuration of the louvered fins had the dominant influence on the heat transfer and pressure drop. They found that a symmetrical arrangement of louvered fins provides more advantage than asymmetrical arrangement in terms of heat transfer and pressure drop. Dogan et al. [8] compared heat transfer and pressure drop characteristics of double-row and triple-row multi-louvered fin heat

Corresponding author: aokbaz@yildiz.edu.tr 
exchangers. They found that the overall performance of double-row fin heat exchanger was more effective. Rugh et al. [9] experimentally studied heat transfer and friction coefficients for high-density louvered fin and flat tube heat exchangers used for passenger compartment heating in automobiles. Suga and Aoki [10] concluded that smaller louver angles were found to provide an overall better performance due to behaviour of thermal wakes. Springer and Thole [11] concluded that to do an experiment with louver fins, enough number of fin rows is needed to simulate flow behaviour of real size heat exchanger. Zhang and Tafti [12] classified thermal wakes interference of multi-louvered fins as inter-fin interference which occurs between adjacent rows of louvers for louver directed flows and intra-fin interference which occurs on subsequent louvers of the same row or fin for duct directed flows. Perrotin and Clodic [13] compared numerical results of $2 \mathrm{D}$ and $3 \mathrm{D}$ louver fin heat exchanger models with wind tunnel tests. The results of $3 \mathrm{D}$ models were closer to the experimental results and $2 \mathrm{D}$ models overestimated significantly the heat transfer coefficient. Hsieh and Jang [14] reported that successively variable louver angles effectively enhance the heat transfer performance. Okbaz et al. [15] studied to determine minimum number of rows which provide periodic flow conditions with adequate flow field to conduct experimental measurements of their test facility. They discussed the flow structure depending on the number of rows

According to literature survey there are several studies which investigate heat transfer and pressure drop characteristics on basic geometrical structures. In this study, thermal and hydraulic performance of a louvered fin heat exchanger that is to be designed for an particular industrial application have been investigated numerically. Results are given in terms of Colburn $\boldsymbol{j}$ factor and Fanning factor $f$, temperature counters and stream-lines results.

\section{Numerical method}

The three dimensional flow field and heat transfer were solved using commercial code ANSYS Fluent. Several turbulence models such as: Standard k- $\epsilon$ turbulence model, RNG $\mathrm{k}-\epsilon$ turbulence model, Realizable k- $\epsilon$ turbulence model, SST-k- $\omega$ turbulence model and RSM were tested. For this louver fin heat exchanger model, experimental study have not been done yet. But, for other louver fin models which are the products of FRITERM Company and similar to current model, There are experimental results to validate numerical model. These experiments have been conducted in the test lab of FRITERM Company. When the heat transfer results of numerical and experimental studies were compared, it was seen that Standard $k-\epsilon$ turbulence model over predicted convective heat transfer coefficient. RNG k- $\epsilon$ turbulence model and Realizable k$\epsilon$ turbulence model predicts convective heat transfer coefficient closer to the experimental results. Reynolds Stress Model (RSM) results are also close to experimental results. However, more CPU time and memory were required to solve via RSM. Hsieh and
Jang [16], used extended k- $€$ turbulence model of Chen and Kim [17] in their numerical study. In this study, we considered separated flow effects of tubes when solving three dimensional flow fields. Due to realizable model provides the best performance of all the k- $\epsilon$ turbulence models of separated flows (ANSYS Fluent Theory Guide [18]), its low cost of running time and its wellknown good performance on solving heat transfer problems, Realizable k-€ turbulence model was used to solve three-dimensional flow field and heat transfer. To solve more accurately wall shear stress and wall heat transfer Enhanced Wall Treatment option for Realizable $\mathrm{k}-\epsilon$ turbulence model was applied. Enhanced Wall Treatment is a near wall modelling method to resolve viscous sublayer and fully turbulent region. A pressure based predictor/multi-corrector solution procedure was employed to enhance velocity-pressure coupling and continuity-satisfied flow filed. The Couple algorithm was applied for solving flow field. The discretization of the convective terms in the governing equations was done via a second order upwind scheme, order central differencing scheme was applied for the diffusive terms. The pressure gradient in the momentum equations was treated via a second order discretization scheme.

The dimensionless equations for continuity, momentum (Reynolds- averaged Navier-Stokes equations) and energy may be expressed in tensor form as:

$$
\begin{aligned}
& \frac{\partial U_{i}}{\partial X_{i}}=0 \\
& \frac{\partial}{\partial X_{j}}\left(U_{i} U_{j}\right)=-\frac{\partial P}{\partial X_{i}}+\frac{1}{\operatorname{Re}}\left[{ }^{\prime 2} U_{i}\right]-\frac{\partial}{\partial X_{j}}\left(\overline{u_{i} u_{j}}\right)
\end{aligned}
$$

The modeled transport equations for $\mathrm{k}$ and $\epsilon$ in the realizable $\mathrm{k}-\epsilon$ model are (ANSYS Fluent Theory Guide[18]):

$$
\frac{\partial}{\partial t}(\rho k)+\frac{\partial}{\partial x_{j}}\left(\rho k u_{j}\right)=\frac{\partial}{\partial x_{j}}\left[\left(\mu+\frac{\mu_{k}}{\sigma_{k}}\right) \frac{\partial k}{\partial x_{j}}\right]+G_{k}+G_{b}-\rho \varepsilon-Y_{M}+S_{k}
$$

$$
\begin{aligned}
& \frac{\partial}{\partial x}(\rho \varepsilon)+\frac{\partial}{\partial x_{j}}\left(\rho \varepsilon u_{j}\right)=\frac{\partial}{\partial x}\left[\left(\mu+\frac{\mu_{t}}{\sigma_{\varepsilon}}\right) \frac{\partial \varepsilon}{\partial x_{j}}\right] \\
& +\rho C_{1} S \varepsilon-\rho C_{2} \frac{\varepsilon^{2}}{k+\sqrt{v \varepsilon}}+C_{1 \varepsilon} \frac{\varepsilon}{k} C_{3 \varepsilon} G_{b}+S_{\varepsilon}
\end{aligned}
$$




$$
C_{1}=\max \left[0.43, \frac{\eta}{\eta+5}\right], \eta=S \frac{k}{\varepsilon}, S=\sqrt{2 S_{i j^{\prime}}}
$$

Here, $G_{k}$ represents the generation of turbulence kinetic energy due to the mean velocity gradients. $G_{b}$ is the generation of turbulence kinetic energy due to buoyancy, $\mathrm{Y}_{\mathrm{m}}$ represents the contribution of the fluctuating dilatation in compressible turbulence to the overall dissipation rate. $C_{1 \epsilon}, C_{2 \epsilon}$ and $C_{3 \epsilon}$ are constants. $S_{k}$ and $\mathrm{S}_{\mathrm{c}}$ are user defined source terms (ANSYS Fluent Theory Guide [18]).

The quality of the mesh was carefully assessed during the meshing. Meshes with five layers of inflation region were established in the close region of the fin wall and tube wall while unstructured tetrahedron meshes were used outer region. The flow field was separated several subfields to satisfy good mesh quality and sensitivity. 12 million elements were used to solve flow field. The near-wall mesh with $y^{+} \leq 1$ was established that fine enough to resolve viscous sublayer. No slip boundary conditions were applied on tube wall surfaces. The walls of louver fins were at constant temperature of $\mathrm{T}_{\mathrm{w}}=313.15 \mathrm{~K}$. The inlet velocity of the flow were $1.22 \mathrm{~m} / \mathrm{s}, 1.52 \mathrm{~m} / \mathrm{s}, 2.28 \mathrm{~m} / \mathrm{s}$ and $3 \mathrm{~m} / \mathrm{s}$ and the temperature of the inlet fluid was set at $30^{\circ} \mathrm{C}$. The turbulence intensity at the inlet is set at $10 \%$. At the exit, pressure outlet boundary condition at operational pressure of $0 \mathrm{~Pa}$ was applied. The distance of the inlet boundary to geometry of interest and the distance of the outlet boundary to geometry of interest is $33 \mathrm{~mm}$ and 99 $\mathrm{mm}$, respectively. Before starting all analysis effects of this distance length were tested. Periodic boundary conditions were applied left- right sides and top-bottom sides of solution domain.

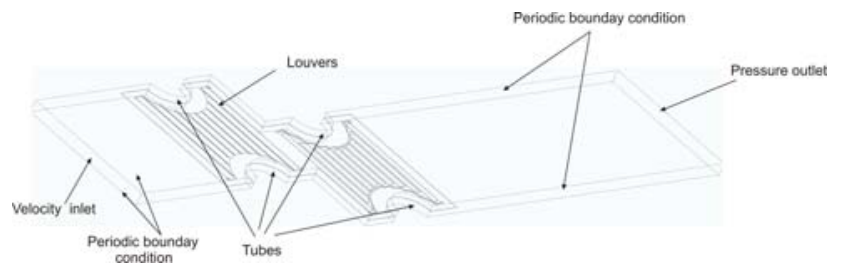

Fig. 13 D computational domain and boundary conditions.

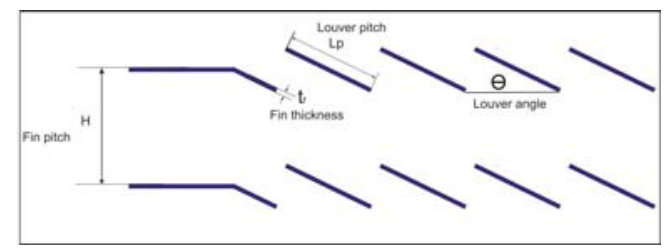

Figure 2 Details of physical model

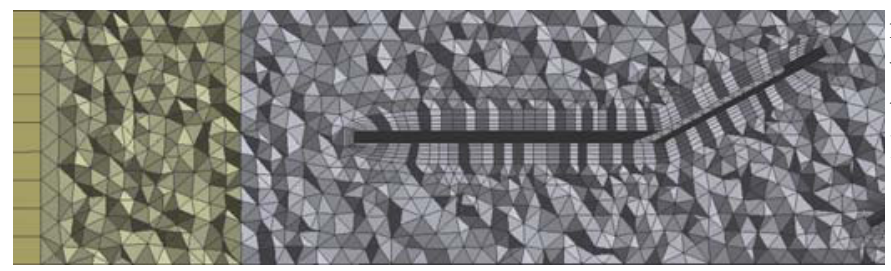

Fig. 3 Detailed view of computational grid system
The Reynolds number is defined as:

$$
\operatorname{Re}=\frac{\rho U H}{\mu}
$$

Where $\mathrm{U}$ is the frontal velocity and $\mathrm{H}$ is the fin pitch.

The averaged heat transfer coefficient $\mathrm{h}$ is defined as:

$$
\begin{gathered}
T_{b}=\frac{T_{\text {in }}+T_{\text {out }}}{2} \\
q^{\prime \prime}=h \cdot\left(T_{w}-T_{b}\right)
\end{gathered}
$$

Here, q" is the total heat flux and $\mathrm{T}_{\mathrm{b}}$ is the bulk mean temperature of the fluid. The averaged heat transfer coefficient can be expressed in dimensionless form by Nusselt number $\mathrm{Nu}$.

The Fanning friction factor $f$ and Colburn factor $j$ are defined as:

$$
\begin{aligned}
& j=\frac{N u}{\operatorname{Re} \cdot \operatorname{Pr}^{2 / 3}}=\frac{h}{\rho \cdot U \cdot C_{p}} \cdot \operatorname{Pr}^{2 / 3} \\
& f=\frac{\Delta P}{\frac{1}{2} \cdot \rho \cdot U^{2}} \cdot \frac{H}{4 \cdot L}
\end{aligned}
$$

Table 1. Geometric and operation parameters

\begin{tabular}{lcl}
\hline $\begin{array}{l}\mathrm{L}_{\mathrm{p}} / \mathrm{F}_{\mathrm{p}} \text { (Ratio of louver } \\
\text { pitch to fin pitch) }\end{array}$ & $1.9,1.52$, & \\
$\begin{array}{l}\text { Louver tilt angle }(\Theta) \\
\text { Fin thickness }\left(\mathrm{t}_{\mathrm{f}}\right):\end{array}$ & $22^{\circ} \leq \Theta \leq 30^{\circ}$ & \\
Flow length $(\mathrm{L}):$ & 0.12 & $\mathrm{~mm}$ \\
Inlet air & 66 & $\mathrm{~mm}$ \\
Temperature $:\left(\mathrm{T}_{\text {in }}\right)$ & 303.15 & $\mathrm{~K}$ \\
Frontal velocity $(\mathrm{U})$ & $1.22 \leq \mathrm{U} \leq 3$ & $\mathrm{~m} / \mathrm{s}$ \\
Wall temperature $\left(\mathrm{T}_{\mathrm{w}}\right):$ & 313.15 & $\mathrm{~K}$
\end{tabular}

\section{Results and discussion}

The hydraulic and thermal performances of a louver fin heat exchanger depend on geometrical details and flow conditions. In Figure 4 and Figure 5 velocity vectors and related streamline patterns coloured with velocity magnitudes are shown, respectively. These visualization results were obtained from top plane view at the periodic boundary region. There occurs a wake region as a result of flow separation around tubes with weaker velocity magnitudes. As seen in Figure 6, the temperature of the cold fluid increases faster in the louvered region of the fin. 


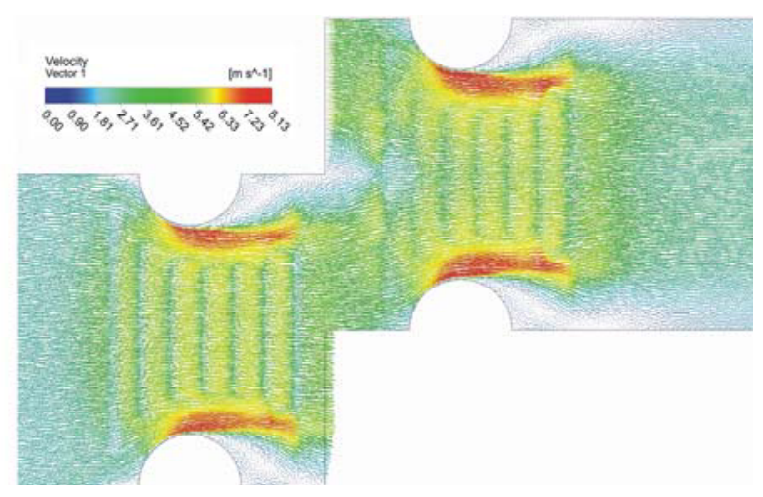

Fig. 4 Velocity vectors for heat exchanger with louver angle of $\Theta=30^{\circ}, L_{p} / F_{p}=1.1875$ and frontal air velocity of $U=3 \mathrm{~m} / \mathrm{s}$. (Obtained from top periodic plane)

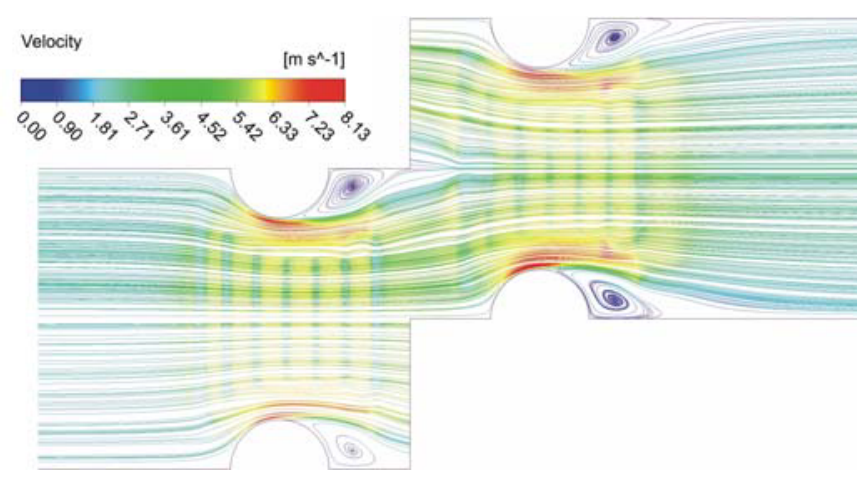

Fig. 5 Streamline patterns for heat exchanger with louver angle of $\Theta=30^{\circ}, L_{p} / F_{p}=1.1875$ and frontal air velocity of $U=3 \mathrm{~m} / \mathrm{s}$. (Obtained from top periodic plane)

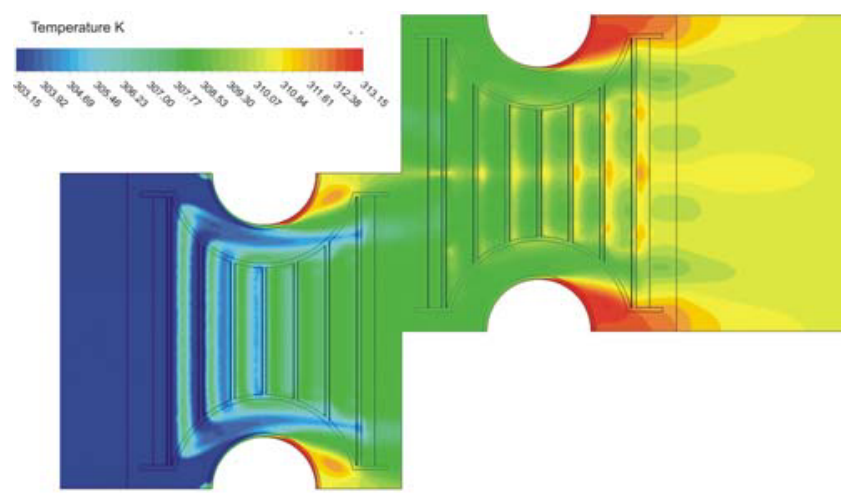

Fig. 6 Temperature counters for heat exchanger with louver angle of $\Theta=30^{\circ}, L_{p} / F_{p}=1.1875$ and frontal air velocity of $U=$ $3 \mathrm{~m} / \mathrm{s}$. (Obtained from top periodic plane)

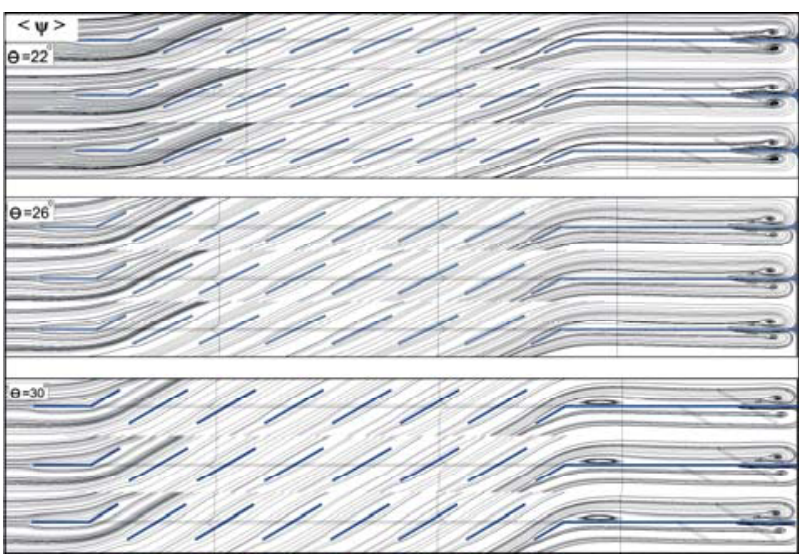

Fig. 7 Streamlines for heat exchanger with louver angle of $\Theta$ $=22^{\circ}, 26^{\circ}$ and $30^{\circ}, \mathrm{L}_{\mathrm{p}} / \mathrm{F}_{\mathrm{p}}=1.1875$ and frontal air velocity of $\mathrm{U}=3 \mathrm{~m} / \mathrm{s}$ (Obtained from middle plane of first louver row.)

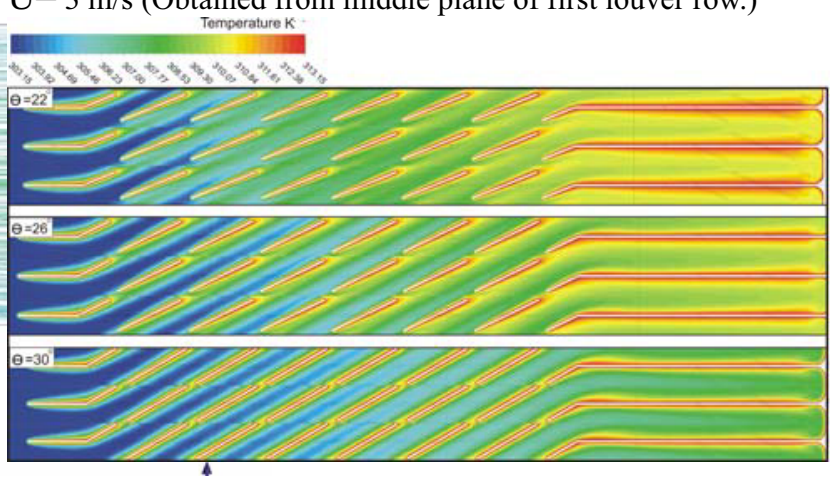

Fig. 8 Temperature counters for heat exchanger with louver angle of $\Theta=22^{\circ}, 26^{\circ}$ and $30^{\circ}, \mathrm{L}_{\mathrm{p}} / \mathrm{F}_{\mathrm{p}}=1.9$ and frontal air velocity of $U=3 \mathrm{~m} / \mathrm{s}$ (Obtained from middle plane of first louver row.)

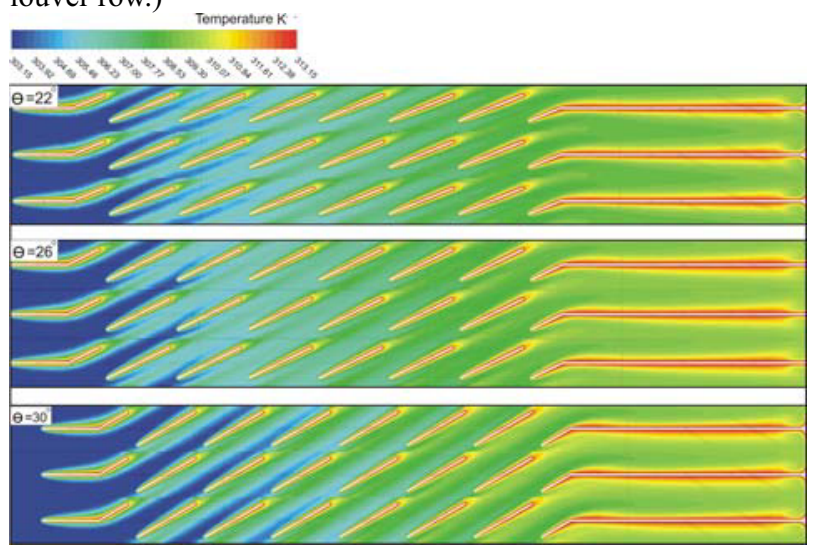

Fig. 9 Temperature counters for heat exchanger with louver angle of $\Theta=22^{\circ}, 26^{\circ}$ and $30^{\circ}, \mathrm{L}_{\mathrm{p}} / \mathrm{F}_{\mathrm{p}}=1.52$ and frontal air velocity of $\mathrm{U}=3 \mathrm{~m} / \mathrm{s}$ (Obtained from middle plane of first louver row.) 


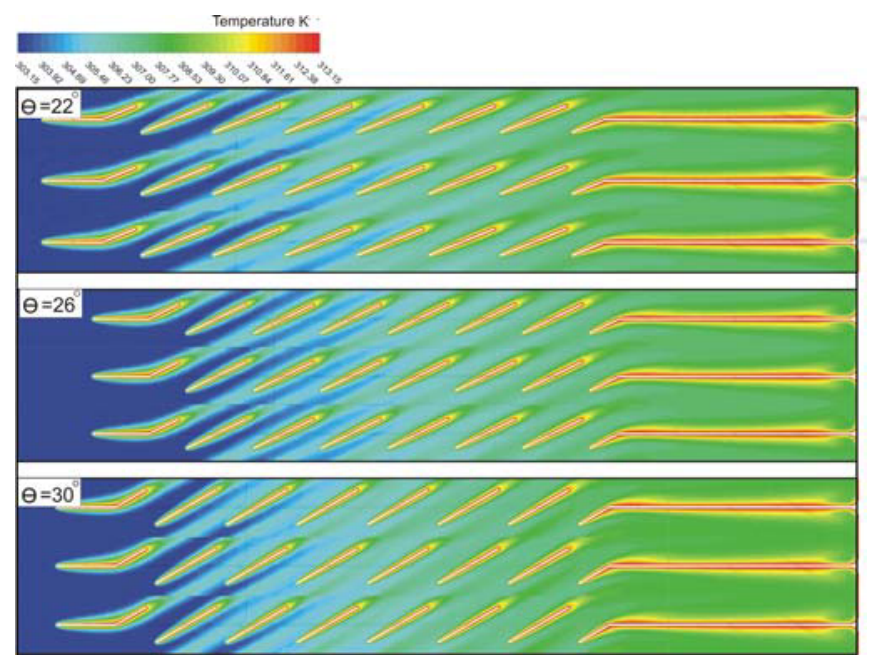

Fig. 10 Temperature counters for heat exchanger with louver angle of $\Theta=22^{\circ}, 26^{\circ}$ and $30^{\circ}, \mathrm{L}_{\mathrm{p}} / \mathrm{F}_{\mathrm{p}}=1.1875$ and frontal air velocity of $\mathrm{U}=3 \mathrm{~m} / \mathrm{s}$ (Obtained from middle plane of first louver row.)
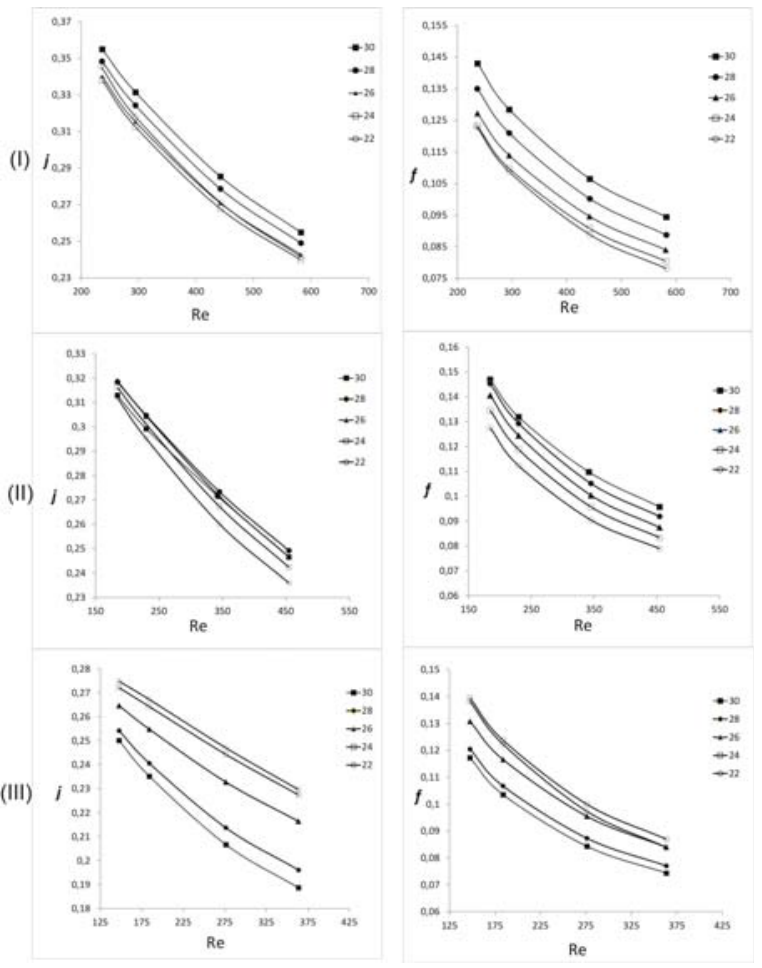

Fig. 11 Colburn factor $\boldsymbol{j}$ and Fanning friction factor $\boldsymbol{f}$ graphics for $\mathrm{L}_{\mathrm{p}} / \mathrm{F}_{\mathrm{p}}=1.1875$ (row I), $\mathrm{L}_{\mathrm{p}} / \mathrm{F}_{\mathrm{p}}=1.52$ (row II) and $\mathrm{L}_{\mathrm{p}} / \mathrm{F}_{\mathrm{p}}=$ 1.9 (row III).

In Figure 7 streamline patterns of inlet louvers are given for $\mathrm{L}_{\mathrm{p}} / \mathrm{F}_{\mathrm{p}}=1.1875$ and louver angles of $22^{\circ}, 26^{\circ}$ and $30^{\circ}$ and frontal air velocity of $3 \mathrm{~m} / \mathrm{s}$. These streamline patterns were determined from side plane in the middle of first row of louvers (inlet louver region). The flow is louver directed for all louver angles. As seen from the streamline patterns, when the louver angle increases, the distance of the flow that air travel across the fins increases. At the end of the inlet louver region and upstream of the tubes a large recirculation region patterns of horseshoe vortex was formed. Sahin et al. [19] experimentally showed the formation of vortexes which are called as horseshoe vortexes for plate-fin and tube heat exchangers via particle image velocimetry technique. They reported that well-known horseshoe vortexes magnified the entrainment process which occurred between the main flow and the wake-flow regions and enhanced the heat transfer rate in the case of fin-tube heat exchangers. For the louver angle of $30^{\circ}$, a flow separation region on downstream direction of the last louver occurred due to high louver angle. This formation increases pressure drop penalty.

The temperature distribution along the louvers is given in Figure 8, 9 and 10 for $\mathrm{L}_{\mathrm{p}} / \mathrm{F}_{\mathrm{p}}=1.9,1.52,1.1875$ respectively at frontal air velocity of $3 \mathrm{~m} / \mathrm{s}$. These temperature counters were also taken from side plane in the middle of first row of louvers. These results give considerable information about heat transfer characteristics. The heating process of cold fluid along the louvers and mixing of cold and hot fluids can be easily seen. As seen from the figures louver angle affects heat transfer differently depending on fin pitches.

In Figure 7 , the temperature counters for louver angles of $22^{\circ}, 26^{\circ}$ and $30^{\circ}$ are given for $\mathrm{L}_{\mathrm{p}} / \mathrm{F}_{\mathrm{p}}=1.9$ at frontal air velocity of $3 \mathrm{~m} / \mathrm{s}$. The exit temperature for the case the louver angle of $22^{\circ}$ is higher due to mixing of cold and hot air is magnified. Increasing the louver angle to $30^{\circ}$ made the distance closer the leading edge and trailing edge of upper and lower fins' louvers. Thus, boundary layer was formed thicker when the fluid flowed along the louvers across the fins. When $\mathrm{L}_{\mathrm{p}} / \mathrm{F}_{\mathrm{p}}$ was decreased to 1.52 , in the case for the louver angle of $22^{\circ}$, heat transfer was higher. In Figure 9 the results of temperature counters are given for $\mathrm{L}_{\mathrm{p}} / \mathrm{F}_{\mathrm{p}}$ is 1.1875 . At this distance of lower and upper fins, the trailing edge and leading edge of louvers are far enough to restart of boundary layer. Thus, increasing louver angle increased heat transfer due to increasing of flow length.

To evaluate quantitatively heat transfer and hydraulic performance for all louver angles, frontal velocities of air and fin pitches, Colburn factor $j$, Fanning friction factor $f$ are given in Figure 11. In the first row of Figure 10, Colburn factor $j$ and Fanning friction factor $f$ is given $\mathrm{L}_{\mathrm{p}} / \mathrm{F}_{\mathrm{p}}=1.1875$. Colburn factor $j$ increased with increasing louver angles. Increased louver angles provide the flow in longer distance by travelling between the neighbour fins. Fanning friction factor $f$ also increased while the louver angle increased as a result of longer flow length. For smaller fin pitch $\left(\mathrm{L}_{\mathrm{p}} / \mathrm{F}_{\mathrm{p}}=1.52\right)$ Colburn factor $j$ decreased compared to case of $\mathrm{L}_{\mathrm{p}} / \mathrm{F}_{\mathrm{p}}=1.1875$. The highest heat transfer occurred for louver angle of $28^{\circ}$ and it was too close the value of $30^{\circ}$. However, the pressure drop is highest for the case the louver angle of $30^{\circ}$. When $\mathrm{L}_{\mathrm{p}} / \mathrm{F}_{\mathrm{p}}=1.9$, the heat transfer and pressure drop characteristics completely changed depending on louver angle. The highest heat transfer value in terms of Colburn factor $j$ was for the case of louver angle of $22^{\circ}$ while the smallest value of it was for the case of louver angle of $30^{\circ}$. Moreover, the lowest pressure drop in terms of Fanning friction factor $f$ 
was for louver angle of $24^{\circ}$ and it was very close to value of $22^{\circ}$ while the highest value was for the case of louver angle of $30^{\circ}$. For louver pitch to fin pitch $\mathrm{L}_{\mathrm{p}} / \mathrm{F}_{\mathrm{p}}$ is equal to 1.9 heat transfer and pressure drop characteristics reversed. The reason of this situation was explained looking temperature distribution results.

\section{Conclusion}

In this study air-side heat transfer and pressure drop characteristics of multi-louvered fin heat exchangers were studied numerically. 3-D numerical simulations was done via ANSYS Fluent software. The heat transfer and pressure drop characteristics were reported in terms of Colburn $j$-factor and Fanning friction factor $f$. The louver angles were changed in the range of $20^{\circ} \leq \Theta \leq 30^{\circ}$, and frontal velocities of $U$ were between $1.22 \mathrm{~m} / \mathrm{s}$ and 3 $\mathrm{m} / \mathrm{s}$. To understand the effect of flow structure on heat transfer and pressure drop characteristics streamline patterns, velocity vectors and temperature counters were given. The following conclusions have been achieved:

- $\quad$ For all louver angles, ratio of louver pitch to fin pitch and operation conditions of frontal velocities, the flow was full louver directed.

- $\quad$ For ratios of louver pitch to fin pitch 1.1875 and 1.52, heat transfer capacity and pressure drop penalties increased with increasing louver angle.

- The effect of louver angle on heat transfer and pressure drop was decreased for $L_{p} / F_{p}=1.52$ compared to case of $L_{p} / F_{p}=1.1875$

- $\quad$ For the ratio of louver pitch to fin pitch $L_{p} / F_{p}=1.9$, Colburn $j$-factor and and Fanning friction factor $f$ decreased with increasing louver angle

\section{ACKNOWLEDGMENTS}

The authors would like to acknowledge the funding of Republic of Turkey Ministry of Science, Industry and Technology and FRITERM Company under project contract number of 0649.STZ.2014. This study has been prepared from ongoing Ph.D. thesis studies of Abdulkerim OKBAZ.

\section{References}

1. H. Aoki, T. Shinagawa, K.K. Suga, Exp. Thermal and Fluid Sci. 2, 293-300 (1989)

2. R.L. Webb, P. Trauger, Exp. Thermal and Fluid Sci. 4, 205-17 (1991)

3. C.C. Wang, C.J. Lee, C.T. Chang, S.P. Lin, International Journal of Heat and Mass Transfer 42, 1945-1956 (1999)

4. M.H. Kim, C.W. Bullard, International Journal of Refrigeration 25, 390-400 (2002)

5. N.C. DeJong, A.M. Jacobi, Experimental Thermal and Fluid Science 27, 237-250 (2003)
6. J. Dong, J. Chen, Z. Chen, W. Zhang, Y. Zhou, Energy Conversion and Management 48, 15061515 (2007)

7. A. Vaisi, M. Esmaeilpour, H. Taherian, Applied Thermal Engineering 31, 3337-3346 (2011)

8. B. Dogan, O. Altun, U. Ugurlubilek, M. Tosun, T. Sarıçay, L. B. Erbay, Applied Thermal Engineering 91, 270-278 (2015)

9. J.P. Rugh, J.T. Pearson, S.A. Ramadhyani, ASME Symp Ser HTD 201, 15-24 (1992)

10. K. Suga, H. Aoki, Proc. of ASME/JSME Thermal Eng. Joint Conf. 4, 361-368 (1991)

11. M.E. Springer, K.A. Thole, Experimental Thermal and Fluid Sci. 18, 258-69 (1998)

12. X. Zhang, D.K. Tafti, International Journal of Heat and Mass Transfer 44, 2461-2473 (2001)

13. T. Perrotin, D. Clodic, International Journal of Refrigeration 27, 422-432 (2004)

14. C.T. Hsieh, J.Y. Jang, Applied Thermal Engineering 26, 1629-1639 (2006)

15. A. Okbaz, A.B. Olcay, A. Pinarbasi, Experimental Fluid Mechanics 2014 393-399 (2014)

16. C.T. Hsieh, J.Y. Jang, Applied Thermal Engineering 26, 1629-1639 (2006)

17. Y.S. Chen, S.W. Kim, NASA CR 179204, (1987)

18. ANSYS Fluent Theory Guide, ANSYS Inc. Canonsburg, 52-53 (2013)

19. B. Sahin, N.A. Ozturk, C. Gurlek, International Journal of Heat and Fluid Flow 29, 340-351 (2008) 